\title{
A Step Forward Standardization of Biocompatibility Testing on Tissue Culture Polystyrene
}

\author{
ANDREI MARIAN FEIER ${ }^{1}$, DOINA RAMONA MANU1', GABRIELA STRNAD ${ }^{3}$, MINODORA DOBREANU1', OCTAV MARIUS RUSSU1, \\ DIANA PORTAN ${ }^{2 *}$, TIBERIU BATAGA ${ }^{1}$ \\ ${ }^{1}$ University of Medicine and Pharmacy Tirgu Mures, 38 Gheorghe Marinescu Str., 540139, Tirgu Mures, Romania \\ 2Department of Mechanical Engineering and Aeronautics, Laboratory of Biomechanics and Biomedical Engineering, University \\ of Patras, Rion 26500, Greece \\ ${ }^{3}$ Petru Maior University, Faculty of Engineering, 1 Nicolae lorga Str., 540088, Tirgu Mures, Romania
}

\begin{abstract}
Standard procedures regarding osteoblastcells deposition on different subtrates to test the biocompatibility of materials are not available. Aspects related to cells morphology depending on their number on the surface area of the substrate were studied for the first time. Osteoblasts were successfully isolated from residual bone resulted from two different patients after total hip arthroplasty. Different numbers of osteoblasts in populations $\left(3 \times 10^{4} \mathrm{cells} / \mathrm{cm}^{2}, 6 \times 10^{4} \mathrm{cell} / \mathrm{s} / \mathrm{cm}^{2}, 1 \times 10^{5} \mathrm{cells} / \mathrm{cm}^{2}\right)$ were deposited on tissue culture polystyrene for 7 and 10 days of incubation. Results suggested that the protocol of osteoblasts deposition should be adjusted to assure a fair distribution of cells on the entire available area of the substrate, possible if a very good dispersion in the medium is achieved prior to deposition. Some other key factors in cells appropriate development, such as substrate nature, topography and incubation time,were detected. The present investigation helps declaring specific standards with respect to the biocompatibility testing of materials using osteoblast populations. Further investigations may lead to the creation of databases and the establishment of standards regarding bicompatibility researches that involve osteoblasts populations.
\end{abstract}

Keywords: tissue culture polystyrene, osteoblasts populations, biocompatibility standards

Osteoblasts are derived from mesenchymal stem cells. The biocompatibility of implantable materials has been evaluated using different methods and models - in particular, in vitro studies using osteoblast cell cultures. During the process of differentiation, these cells pass through a number of distinct stages that can be characterized by the pattern of expression of osteoblastic marker proteins [1]. The isolation of osteoblast cells from residual bone obtained during an orthopedic surgery may be difficult and needs repeated trials. The earliestreport to describe the isolation of viable cells from adulthuman bone is that of Bard et al [2]. The isolation procedure they employed involved extensive demineralization of the tissue in a solution of ethylenediaminetetraacetic acid (EDTA) followed by digestion with collagenase. The cells obtained expressed low levels of alkaline phosphatase and remained viable for periods of up to 2 weeks, but failed to proliferate leading the authors to conclude that osteocytes were the predominant cell type present.

Osteoblasts and their precursors are known as resistant cells, with strong adaptation capacity, which is one of the reasons of their use in biocompatibility studies. However, standard procedures to test the substrates are not yet available. Cells development, reproduction and homogeneous spreading on the entire tested surface of the substrate are clearly influenced by the initially deposited number of cells. Cells kinetics is saddled in vitro, comparing to in vivo where physiological body fluids as well as other factors enhance all their functions and their communication with similar or different bone tissue component cells. Some aspects related to cells deposition on substrates, especially on rough materials such as orthopedic metals and alloys should be adjusted. Moreover, various numbers of osteoblasts ranging from 5.000 to $10^{5}$ / $\mathrm{cm}^{2}$ or even more are deposited on materials in different

*email: diana.portan@gmail.com studies, while constant values should be maintained to assure comparability. Thus, Uggeri et al [3] studied the adhesion of human osteoblasts to titanium and used for all experiments osteoblasts at a density of $\sim 5.000 \mathrm{cell} / \mathrm{s} / \mathrm{cm}^{2}$. On the other hand, more complex studies involving various cell numbers in populations were performed by Martin et al much earlier [4], in a study on the effect of titanium surface roughness on the proliferation, differentiation and protein synthesis of osteoblasts-like cells. Populations containing from $10^{4}$ until $6 \times 10^{4}$ cells were used in his study; in several other studies similar cell numbers were seeded $[5,6]$. In other investigations, much higher cell populations were deposited on the tested substrates [7]. In such cases, a comparative study between different literature results is difficult.

In the frame of the present study, observations have been made related to osteoblasts deposition protocol, their kinetics, development and proliferation when cultured on tissue culture polystyrene in different numbers and for various incubation periods.

\section{Experimental part}

Osteoblasts isolation and differentiation

Osteoblasts were isolated from residual bone obtained from patients undertaking total hip arthroplasty and total knee replacement surgeries. Bone fragments were harvested from the following anatomical locations: femoral head and neck, distal femoral condyles (anterior and posterior), anterior and posterior knee chamfers and tibial plateau. After harvesting, bone fragments $(0.5-2$ $\mathrm{cm}^{3}$ were immediately immersed in culture medium. The culture medium contained: Alpha Minimal Essential Medium (Sigma Aldrich M4655) with 10\% Fetal Bovine Serum (Sigma Aldrich F7524), 50 $\mathrm{gg} / \mathrm{mL}$ Amphotericin B (Sigma Aldrich A2942), 25 $\mathrm{g} / \mathrm{mL}$ Gentamycin (Sigma Aldrich G1397), 50ig/ml L-ascorbic Acid (Sigma A4403) 
and 10-4 M Dexamethasone (Sigma Aldrich D4902). Cells are partially released from bone fragments by centrifugation. An angular frequency of $2500 \mathrm{r} / \mathrm{min}$, for 10 to at most $15 \mathrm{~min}$ is considered appropriate. If residual bone is made of large pieces, these should be fragmented with a scalpel before centrifugation; all these procedures must be undertaken under a laminar flow cabinet in perfectly sterile conditions. The bone fragments and the osteoblasts-differentiating medium were incubated at $37^{\circ} \mathrm{C}$ in a humidified atmosphere containing $5 \% \mathrm{CO}_{2}$. Medium with bone pieces has been removed after two days, the flasks were regularly cleaned, and clean medium has been added every two days. After 3-10 days, first osteoblasts were observed on the bottom of the flask with an inverted Leica DMi8 microscope.

\section{Osteoblasts deposition on the testing substrates}

24 well plates made of tissue culture polystyrene (TCP) have been used as a substrate for this study. The TCP plates were sterile as provided by the supplier. A hemocytometer (Neubauer chamber) was used for cell counting and to prepare dilutions with specific cell numbers [8]. Osteoblasts were cultured on the polystyrene substrates for 7 and 10 days in numbers of $3 \times 10^{4}, 6 \times 10^{4}$ and $1 \times 10^{5}$ cells/ $\mathrm{cm}^{2}$. A very low quantity of cells suspension, as calculated, was released in the center of each specimen. Immediately after deposition, the respective well plates were left for 5 hours in the incubator to induce fastadhesion of osteoblasts to the substrates. Afterwards, medium was added to cover the entire surface of each well. After 7 and 10 days of incubation, cells were fixed on the substrates by immersion in a $2.5 \% \mathrm{w} / \mathrm{vglutaral}$ dehyde solution in phosphate buffered saline (PBS), for $60 \mathrm{~min}$.

\section{Analyses tools}

Observations have been made in phase contrast with an inverted Leica DMi8 microscope. Image I (National Institutes of Health, Bethesda, Maryland, USA) and Excel (Microsoft, Redmond, Washington, USA) software were used to measure, process and manage the interpretation of the data.

\section{Results and discussions}

\section{Osteoblasts isolation, differentiation, deposition on} substrates and optical observation

Depending on the surgery type (knee, hip), a reduced number of mesenchymal stromal cells (MSCs) or osteoblasts precursors may be found in the residual bone tissue that results after surgery. In the present investigation, residual bone extracted from two patients were used to isolate osteoblasts. Special attention has been given to the transportation procedure of the residual bone from the surgery room to the laboratory to eliminate any risk of contamination. On the other hand, it is important to establish some common rules of cells extraction, as for instance the time of centrifugation and the angular frequency (rpm). A threshold shall be considered, as even a light damage of their membrane will result in an unbalanced functional activity. Previous investigations involved human bone marrow cells obtained by aspiration from the femoral diaphysis of patients undergoing total hip replacement surgery. A single-cell suspension was prepared by aspirating the cells successively through 19 and 21-gauge needles [9]. However, an important aspect has been lately considered related to the fact that mechanical stimuli affect osteoblasts behavior [10, 11]. As much as the isolation process is simplified from technical point of view, as better in getting a closer in vitro behavior to the in vivo one. Furthermore, an important aspect related to the survival of osteoblast cells population is related to the number of isolated cells. The proliferation of these cells is possible only if an intense communication exists between them. This is independent on the researcher, as cells extraction followed by their adherence to the flask bottom is random and uncontrollable. However, it is good to know that repeated light movements of the cell culture medium together with the residual bone pieces shall be made for a better mixing of all nutrients and of the isolated osteoblasts before introducing the flasks in the incubator. In the sequence, selected microscopic images of osteoblast seeded in various numbers $/ \mathrm{cm}^{2}$ on polystyrene substrate are shown (fig. 1).

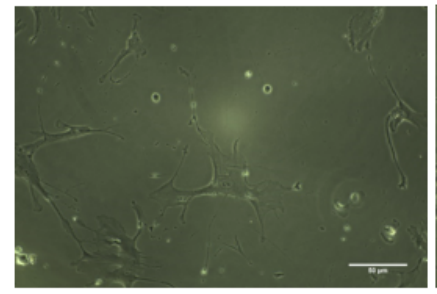

(a)

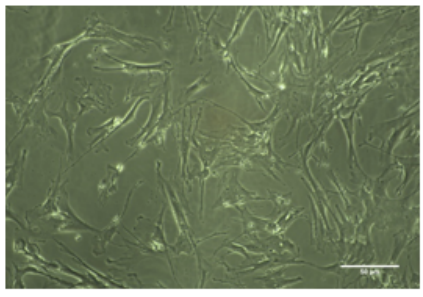

(b)

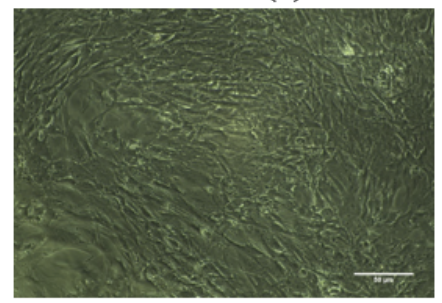

(c)

Fig. 1. Selected optical images under bright field optical microscopy after 7 days of incubation at $37^{\circ} \mathrm{C}$ and $5 \% \mathrm{CO}_{2}$ for (a) 30.000 cells/well (b) 60.000 cells/well and (c) 100.000 cells/well

As observed in figure 1, two types of regions exist on the samples: (i) relaxed regions, meaning regions were osteoblasts are developing by extending their actin filaments in a circular/ oval shape around their nuclei and (ii) confluent regions, meaning regions were osteoblasts are interconnected and form a confluentlayer on the entire analyzed zone. Osteoblasts migration is a widely studied phenomenon due to its complexity and dependence on a wide number of parameters [12]. Generally, osteoblasts are isolated in agglomerations and after their intense proliferation begins, they start migrating on the entire surface of the flask bottom to find new fields to populate. Thereof, they regulate their shape and dimensions depending on the available area. Parameters influencing cells migration and spreading shall be controlled when studying the biocompatibility of different substrates. Cells number in populations $\left(3 \times 10^{4}, 6 \times 10^{4}\right.$ or $\left.10^{5} / \mathrm{cm}^{2}\right)$ have been chosen after literature consulting [7]. These numbers have been found too high for a polystyrene substrate. Osteoblasts proliferate very fast on this kind of substrate due to the smooth topography of the material. On rough substrates adhesion is stronger and migration or multiplication rhythm is tardy. In some materials e.g. titanium, electrostatic forces interfere as well [12] making the entire process even more complex.

Usually, some general features to what concerns osteoblasts behavior can be decoded during their first 10 days of development. Healthy, physiological osteoblasts can be seen at the flask bottom in the first week after tissue extraction, while within 10 days after isolation they already start multiplying. When starting an investigation with osteoblasts, it must be payed attention to the number of days calculated to run the experiments. For longer 
periods, a reduced cells number shall be involved. By carefully analyzing the microscopic images in figure 1, one may find the osteoblast cells crowded. Indeed, the confluent regions are extremely dense, thus not permitting to the cells to develop. Such confluent regions determine a fast aging of cells, by forcing them into their last life cycle which in vivo is associated to an arrangement in dense layers ready for mineralization. Firstly, it is suggested to apply a lower cells concentration (a maximum of $5 \times 10^{4}$ cells $/ \mathrm{cm}^{2}$ ) for a period of maximum 10 days of experimentation on polystyrene substrates. If a comparative study is planned, involving other substrates that induce stronger adhesion of cells, this number may be lightly increased. For longer experimentation periods (e.g. 21 days), the concentration of cells suspension shall be even lower $\left(10^{4} \mathrm{cell} / \mathrm{s} / \mathrm{cm}^{2}\right)$. Secondly, especially when rough substrates are involved, it is recommended to adapt the deposition procedure of the cell suspension to the needs of the sample. One way is by preparing more diluted cells suspension to assure the floating of the osteoblasts for longer periods over the substrate, within the medium. During these hours before final adhesion takes place, osteoblasts scan the surface and gradually adapt to its features. A higher amount of medium means a larger covered area of the sample, and increased possibility for cells to spread on complex substrates, such as the rough ones.

\section{Development of Osteoblast Populations on Tissue Culture Polystyrene}

Preliminary results have shown that osteoblasts initial number in the culture influences on a great extent their kinetics, multiplication and progress. Cumulated results were concentrated in several diagrams to manage an interpretation of osteoblast population behavior. Analyzing them one may understand the kinetics of the population, as well as significant changes that took place between days 7 and 10 of incubation. The firstten days of osteoblasts growth are very important for the faith of the entire population. It must be mentioned that the measurements of osteoblasts' width in populations of $10^{5}$ cells in confluent areas were not included in the diagrams for the interpretation of the results; due to exaggerate agglomeration in this population, osteoblasts had a pronounced spindle-like shape and widths values were not considered representative for the study. Also, for easier interpretation of cells kinetics, populations with higher difference in the cells number ( $3 \times 10^{4}$ and $10^{5}$ cells) were compared in the diagrams in figures 2-3. However, all results including populations of $6 \times 10^{4}$ cells are compared in figure 4.

We observe in figure $2 a$ that osteoblasts length considerably differs after 7 days of incubation, comparing to 10 days of incubation. The multiplication process of physiologic osteoblasts starts at the end of the first week of incubation, while two or three weeks of incubation are needed to have a confluent flask. Knowing this, it is assumed that this process coincides with the selfadjustments of osteoblasts for both length and width ( fig. $2 \mathrm{~b}$ ) to produce space for new cells that will result after multiplication. This self-adjustment is not that obvious in confluent areas (fig. 2c). This is because in confluent areas osteoblasts are arranging themselves from the beginning in such a way to save space, taking a spindle-shaped form.

The diagrams in figures 3 show osteoblasts lengths and widths after 10 days of incubation, for different numbers of deposited cells. It is interesting to notice that in relaxed areas both length and width (figs.3a and b) are presenting

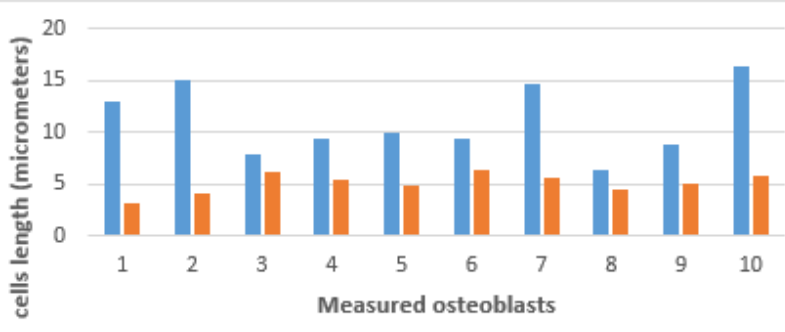

- Relaxed/Day 7/30.000 $\backsim$ Relaxed/ Day 10/30.000

(a)

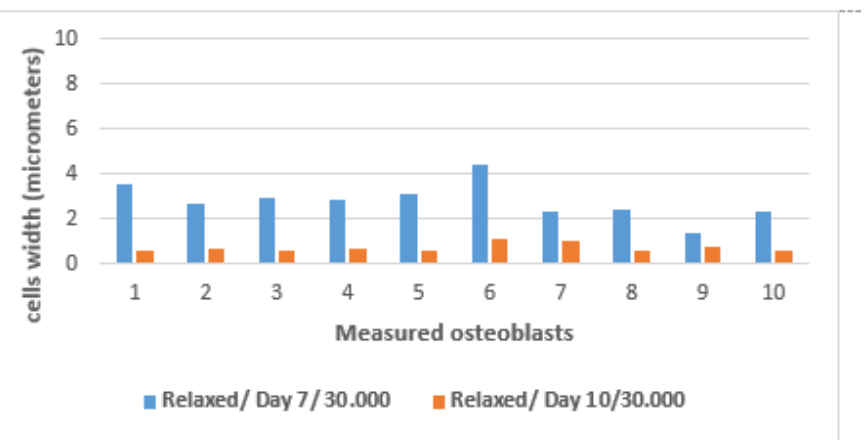

(b)

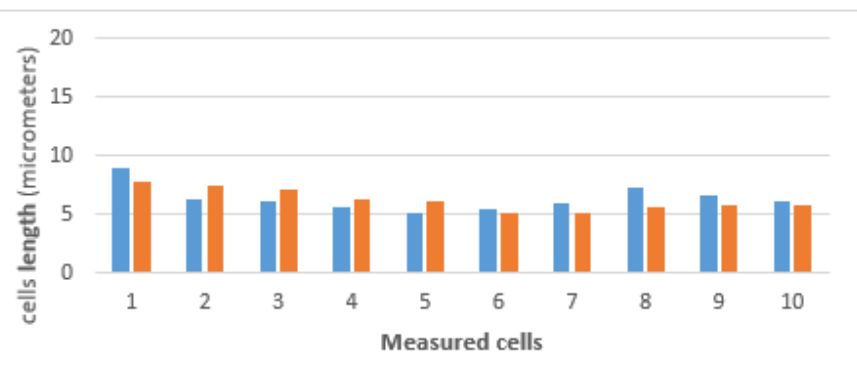

aConfluent/ Day 7/30.000 @ Confluent/ Day 10/30.000

(c)

Fig. 2. Measured cells: (a) lengths and (b) widths, in a population with $3 \times 10^{4}$ osteoblasts, after 7 and 10 days of incubation, in a relaxed area; and (c) length in a population with $3 \times 10^{4}$ osteoblasts, after 7 and 10 days of incubation, in a confluent area

increased values in populations with $10^{5}$ cells $/ \mathrm{cm}^{2}$ comparing to $3 \times 10^{4} \mathrm{cell} / \mathrm{s} / \mathrm{cm}^{2}$, which was expected due to an intensified communication between cells. In confluent areas (fig. 3c), the opposite happens, meaning that a lower osteoblasts number in the initial population assures higher values of their length, while a higher initial osteoblasts number in a population on the same surface area determines restrictions regarding their development.

Between all measured categories, the highest lengths belong to the group of cells that were cultured in a population of $3 \times 10^{4} / \mathrm{cm}^{2}$. This is attributed to cells need of communication that determines a distance reduction between them [13]. It is well known that if cells number in a population is nothigh enough and distance between them is too long, apoptosistakes place, especially when exposed

to shear and mechanical stress [14]. Thus, higher length assures shorter distances between cells. However, since cells do have enough space to develop, they maintain high widths as well. On the other hand, after prolonged incubation time ( 10 days) cells overpass the proliferation threshold; further on, they do have the capacity to adjust 


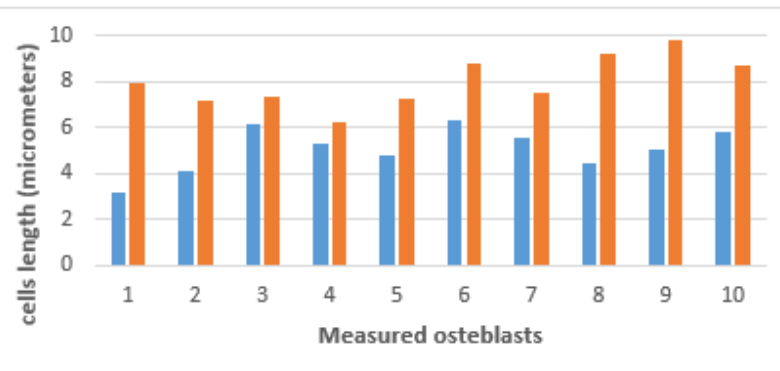

nelaxed/ Day 10/30.000 $\square$ Relaxed/ Day 10/100.000

(a)

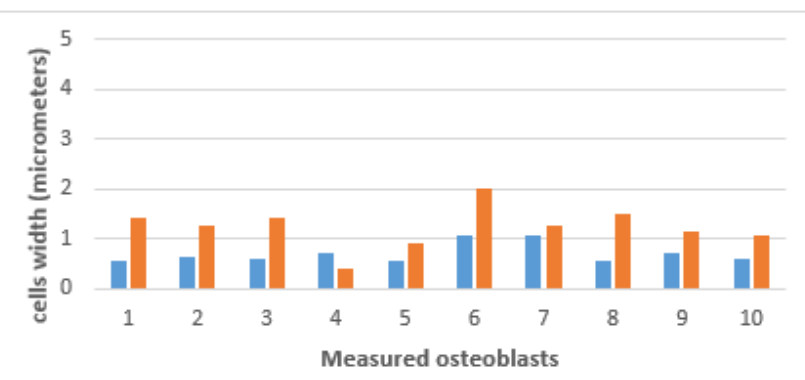

- Relaxed/ Day 10/30.000 ERelaxed/ Day 10/100.000

(b)

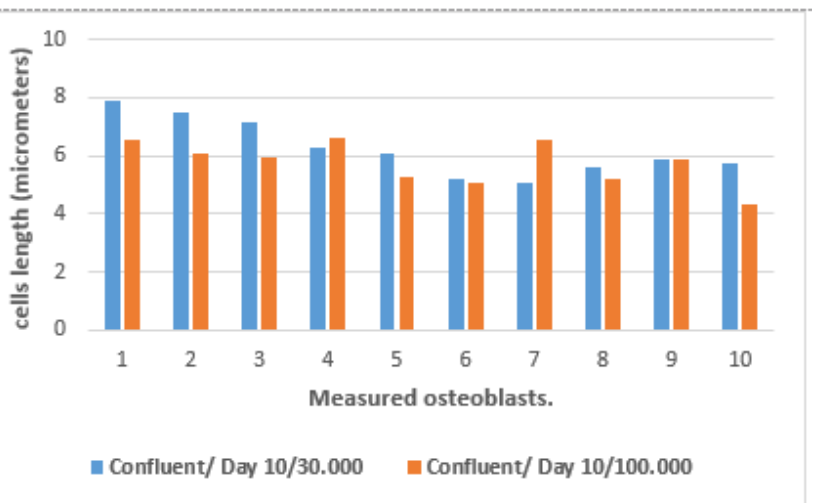

(c)

Fig. 3. Measured cells values of: (a) lengths and (b) widths in populations with $3 \times 10^{4}$ and $10^{5}$ osteoblasts, after 10 days of incubation, in a relaxed area; and (c) lengths in populations with $3 \times 10^{4}$ and $10^{5}$ osteoblasts, after 10 days of incubation, in a confluent area

their length and maintain their width, as it is normal for this type of cells which naturally have a pronounced oval shape. After 3 more days of culture (from 7 to 10 days) a shortening of cells length takes place. At increased cell numbers, for instance $10^{5} \mathrm{cell} / \mathrm{s} / \mathrm{cm}^{2}$ the distance between cells is short enough but the space is much reduced. In this situation osteoblasts have a natural tendency to maintain high lengths and reduced widths with the purpose to save space. In areas of the substrate where cells are confluent, their lengths are much reduced. Agglomeration automatically reverses some proliferative processes. Again, a reduced population and incubation time (7 days) leads to the development of cells with higher lengths than after longer incubation periods ( 10 days), but differences are not that significant as in the case of the relaxed areas. Also, there is an insignificant interplay between reduced cells number $\left(3 \times 10^{4}\right)$ and high cells number $\left(10^{5}\right)$ for confluent areas compared to relaxed areas. Lack of mobility does notallow cells to migrate and take advantage of the entire available area of the substrate. It seems that independently on their number, confluent cells keep standard lengths, while the role of the incubation time is less important.

Finally, the mean values of both legths and widths in all studied populations are compared in the diagram in figure 4. Some highlights are that only in the population with $10^{5}$ cells, their lengths present decreased values in both relaxed and confluent areas, indicating that such high numbers of cells $/ \mathrm{cm}^{2}$ shouldn't be used on polystyrene substrates because osteoblasts have no freedom to self-adjust their dimesions due to lack of space. Further on, for populations of $6 \times 10^{4}$ cells, length and width values are constant for both relaxed and confluent areas, which indicates high stability in the population and that both communication and available area are appropriate for cells to develop normally.

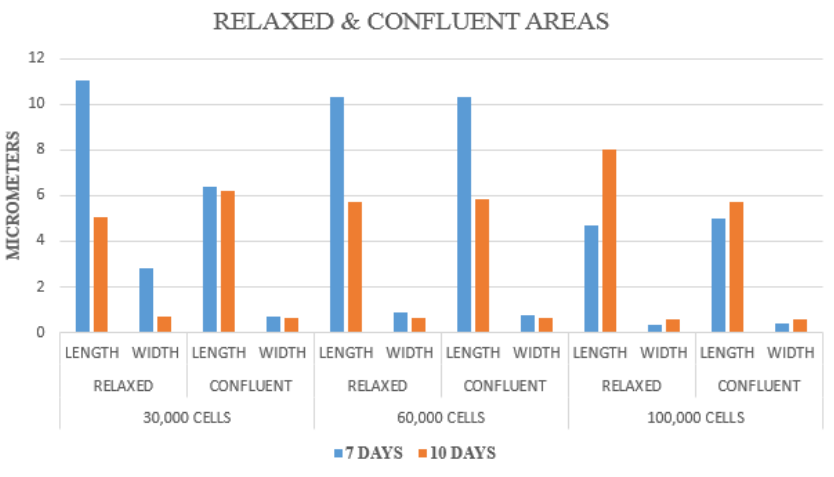

Fig. 4. Mean values of both legths and widths in all studied populations

\section{Conclusions}

Osteoblast bone cells are commonly used to test the biocompatibility of different synthetic substrates. Osteoblasts behavior is complex and under the control of many signaling molecules. Their functioning mechanisms are strongly substrate-dependent and have not yet been fully described. The topography of implantable biomaterials is critical to guide cellular behavior like adhesion, spreading and cells development. Issues such as osteoblasts morphology - in terms of length, width and shape, with respect to their number in an in vitro population and the distance between cells must be clarified. To study the biocompatibility, osteointegration, osteoconductivity and biodegradation properties of some new implantable materials, the first step of the present ongoing research was to establish the optimal conditions for the isolation and differentiation of osteoblasts when seeded on tissue culture polystyrene substrates and to monitor their development, as well as kinetics in relation to the initial number of cells on a specific area. Cells number shall be adjusted taking into consideration both the available area of the substrate and its nature. In the case of tissue culture polystyrene, its smooth surface assures fast migration and proliferation. Cells number in the deposited population should be increased in the case of rough metallic substrates, where migration is delayed because of strong adhesion. Further on, the final goal was to establish an optimized protocol and find the key physical parameters that influence osteoblasts kinetics. According to the findings, it is suggested that a standard procedure of cells deposition and monitoring, depending on substrate's nature, shall be applied when studying materials biocompatibility. 
Acknowledgements: This work was supported by a grant of the Romanian National Authority for Scientific Research and Innovation, CNCS/CCCDI-UEFISCDI, project number PN-III-P2-2.1-PED-2016-0142, within PNCDI III.

\section{References}

1.ROYCE, P.M., STEINMANN B., Tissue and its Heritable Disorders, Molecular, Genetic, and Medical Aspects, 2, Wiley-Liss, 2003, p. 1191. 2.BARD, D.R., DICKENS, M.J ., SMITH, A.U., ZAREK, J.M., Nature., 236 , 1972, p. 314-315.

3.UGGERI, J., GUIZZARDI, S., SCANDROGLIO, R., GATTI, R., Micron., 41, nr. 3, 2010, p. 210-219.

4.MARTIN, J.Y., SCHWARTZ, Z., HUMMERT, T.W., SCHRAUB, D.M., Simpson, J., J. Biomed. Mater. Res., 29, nr. 3, 1995, p. 389-401.

5.NEBE, B., LUTHEN, F., LANGE, R., BECKER, P., BECK, U., Materials Science and Engineering: C., 24, nr. 5, 2004, p. 619-624.

6.SUN, H., WU, C., DAl, K., CHANG, J., TANG, T., Biomaterials., 27, nr. 33,2006, p. 5651-5657.
7.BANFI, A., MURAGLIA, A., DOZIN, B., MASTROGIACOMO, M., CANCEDDA, R., Exp. Hematol., 28, nr. 6, 2000, p. 707-715.

8.MARCHENKO, S., FLANAGAN, L., J. Vis. Exp., 1, nr. 7, 2007, p. 262. 9.PORTAN, D.V., ANTHI, A., PAPANICOLAOU, A.G., Journal of Biomedical Materials PART A., 100A, nr. 10, 2012, p. 2546-2553.

10.KADOW-ROMACKER, A., DUDA, G.N., BORMANN, N., Transfus. Med. Hemother., 40, nr. 6, 2013, p. 441-447.

11.TRAMBITAS, C., POP, T.S., MIRON, A.D.T, Rev. Chim. (Bucharest), 68, no. 2, 2017, p. 387-389.

12.J EONG-KEE, Y., NAM, K.H., HO, B.S., Tissue Engineering Part A., 22, 7-8, 2016, p. 654-664.

13.KABASO, D., GONGADZE, E., PERUTKOVA, S., MATSCHEGEWSKI, C., KRALJ-IGLIC, V., Comput. Methods Biomech. Biomed. Engin., 14, nr. 5, 2011, p. 469-482.

14.FLEACA, R., CERNUSCA, M.S., OLEKSIK, V., OLEKSIK, M., ROMAN, M., Mat. Plast., 54, no. 2, 2017, p. 402-417.

Manuscript received: 7.06 .2018 